\title{
Therapeutic Toxicity of Sunshine Vitamin with Zeitgeber
}

\section{Times}

\begin{abstract}
Tanveer $\mathrm{AK}^{*}$
Scientific Officer, National Institute of Health, Pakistan

*Corresponding author: Tanveer Ahmed Khan, Scientific Officer, Drugs Control and
\end{abstract}

Traditional Medicines Division, National Institute of Health, Pakistan, Tel: +92-320-

288-2884; Email: tanveerahmedkhan754@gmail.com

\section{Editorial \\ Volume 2 Issue 2}

Received Date: September 28, 2019

Published Date: October 11, 2019

DOI: $10.23880 /$ aabsc- 16000141

\section{Editorial}

Vitamin D is a vitamin found in fewer amounts in most of world population. More than $40 \%$ American adults and $65 \%$ Pakistani population have deficiency of this vitamin [1]. It is synthesized in skin. Ultraviolet radiations penetrate into the epidermis when a body is exposed to sunlight. Body photolysis pro vitamin $\mathrm{D}_{3}$ to pre vitamin $\mathrm{D}_{3}$ and ultimately to vitamin $\mathrm{D}_{3}$ [2]. Therefore, it is also called as "the sunshine vitamin". It is an essential component of our optimal health [3]. It also directs cells for absorption of calcium and phosphorus, the major source of strong bones. Low vitamin $\mathrm{D}_{3}$ levels may lead to serious health disorders such as osteoporosis, cancer, depression, muscle weakness etc [4]. In addition, only a handful of foods contain significant amounts of vitamin $D_{3}$. These include cod liver oil, swordfish, salmon, canned tuna, beef liver, egg yolks and sardines. However, sunlight is an important source of vitamin $\mathrm{D}_{3}$ intake. It is important here to note that ultraviolet rays of sun cannot penetrate through windows. So, people who work in front of sunny windows are unable to get vitamin $D_{3}$. Vitamin $D_{3}$ is beneficial even in large amounts because Melanoma (the deadliest skin cancer) is often found on the least exposed areas of body to sun. Similarly, occupational skin exposure is associated with reduced risk of Melanoma [5].

Vitamin $D_{3}$ is necessary for our optimal health and one source of this sunshine vitamin is sunlight but one question arises here. At which time, one should expose the skin to get sufficient amount of vitamin $\mathrm{D}_{3}$ ? In summer season, middle of the day is best time to expose against sunlight. Ultraviolet rays are most intense at this time and one needs to expose less in sun to get sufficient amount of this vitamin [6]. Various studies suggested that noon is the best time when body makes vitamin $\mathrm{D}_{3}$ efficiently [7,8]. In United Kingdom, 10-15 minutes of exposure to sun, three times a week, is sufficient to maintain vitamin $\mathrm{D}_{3}$ levels while in Pakistan, 6-8 minutes are sufficient [6]. However, 30 minutes of exposure to sunlight is necessary in Scandinavian countries to consume 10,000 to 20,000 IU of vitamin $D_{3}$ [9]. Exposure to sun in late hours or in afternoons may increase the risk of various skin cancers [10]. This exposure of body to sunlight is good to get vitamin $\mathrm{D}_{3}$ but how much skin should offer to get sufficient vitamin $D_{3}$. Some scientists and experts recommend that one third of skin area should be exposed to sun for sufficient vitamin $\mathrm{D}_{3}$ intake [6].

There is also a myth that it is easy to overdose on vitamin $D_{3}$. Vitamin $D_{3}$ toxicity is very rare and only happens if one takes very high doses for extended periods [11]. Consequently, excess of vitamin $\mathrm{D}_{3}$ through sunlight with respect to zeitgeber time is not bad and we can claim vitamin $\mathrm{D}_{3}$ a therapeutic toxic.

\section{References}

1. Forrest KY, Stuhldreher WL (2011) Prevalence and correlates of vitamin D deficiency in US adults. Nutrition research 31(1): 48-54.

2. Holick MF, Smith E, Pincus S (1987) Skin as the site of vitamin $\mathrm{D}$ synthesis and target tissue for 1, 25dihydroxyvitamin D3: use of calcitriol $(1,25-$ dihydroxyvitamin D3) for treatment of psoriasis. Archives of dermatology 123(12): 1677-1683a. 
3. Holick MF (2016) Biological effects of sunlight, ultraviolet radiation, visible light, infrared radiation and vitamin D for health. Anticancer research 36(3): 1345-1356.

4. Holick MF (2007) Vitamin D deficiency. New England Journal of Medicine 357(3): 266-281.

5. Kennedy C, Bajdik CD, Willemze R, De Gruijl FR, Bouw es Bavinck JN, et al. (2003) The influence of painful sunburns and lifetime sun exposure on the risk of actinic keratoses, seborrheic warts, melanocytic nevi, atypical nevi, and skin cancer. J Invest Dermatol 120(6): 1087-1093.

6. Rhodes LE, Webb AR, Fraser HI, Kift R, Durkin MT, et al. (2010) Recommended summer sunlight exposure levels can produce sufficient ( $\geq 20 \mathrm{ng} \mathrm{ml}-1$ ) but not the proposed optimal ( $\geq 32 \mathrm{ng} \mathrm{ml}-1) 25(\mathrm{OH}) \mathrm{D}$ levels at UK latitudes. Journal of Investigative Dermatology 130(5): 1411-1418.
7. Harinarayan CV, Holick MF, Prasad UV, Vani PS, Himabindu G (2013) Vitamin D status and sun exposure in India. Dermato-endocrinology 5(1): 130141.

8. Alshahrani FM, Almalki MH, Aljohani N, Alzahrani A, Alsaleh Y, et al. (2013) Vitamin D: Light side and best time of sunshine in Riyadh, Saudi Arabia. Dermatoendocrinology 5(1): 177-180.

9. Cicarma E, Porojnicu AC, Lagunova Z, Dahlback A, Juzeniene A, et al. (2009) Sun and sun beds: inducers of vitamin D and skin cancer. Anticancer research 29(9): 3495-3500.

10. Moan J, Dahlback A, Porojnicu AC (2008) At what time should one go out in the sun? Adv Exp Med Biol 624: 86-88.

11. Hathcock JN, Shao A, Vieth R, Heaney R (2007) Risk assessment for vitamin D. The American journal of clinical nutrition 85(1): 6-18. 